EESTI NSV TEADUSTE AKADEEMIA TOIMETISED. 25. KOIDE

FUOSIKA * MATEMAATIKA. 1976, NR. 1

ИЗВЕСТИЯ АКАДЕМИИ НАУК ЭСТОНСКОП ССР ТОМ 25 ФИЗИКА * МАТЕМАТИКА. 1976, № 1

удК 535.853 .68

B. ТИИТ

\title{
КОМПЕНСАЦИОННАЯ СИСТЕМА РЕГИСТРАЦИИ К ВАКУУМНОМУ МОНОХРОМАТОРУ
}

V. TIIT. KOMPENSEERIV REGISTREERIMISSUSTEEM VAAKUUMMONOKROMAATORILE

V. TIIT. COMPENSATORY RECORDING SYSTEM FOR VACUUM MONOCHROMATOR

При исследованиях в вакуумной ультрафиолетовой области спектра в качестве источника света обычно используется водородная разрядная лампа. Однако присутствие в спектре излучения водорода множества линий затрудняет обработку измерений $\left[{ }^{1,2}\right]$.

Устранение влияния вида спектра источника света на результаты эксперимента легче осуществить, применяя двухлучевые монохроматоры, где этот процесс можно относительно легко автоматизировать разными методами. Упомянем здесь два из них.

1. Автоматическое деление сигнала от исследуемого образца в измерительном канале на сигнал, пропорциональный интенсивности выходящего монохроматического света в другом, опорном канале [3-8].

2. Поддерживание постоянного уровня интенсивности монохроматического излучения путем использования света одного канала для автоматического регулирования мощности радиации, выходящей из прибора. Это достигается либо изменением силы разрядного тока лампы $\left[{ }^{1}\right]$, либо изменением ширины щелей с одновременным применением серого клина в опорном канале для выравнивания света в опорном и измерительном каналах $\left[{ }^{9}\right]$.

Нами была предпринята попытка объединить оба метода и дополнить монохроматор и самописец устройством для нанесения отметок длин волн на спектрограмму. Это, по нашему мнению, делает систему регистрации более гибкой и об̆легчает работу на монохроматоре, особенно в тех случаях, когда реакция исследуемого образца на излучение имеет сложную зависимость от длины волны света.

Интенсивность выходящего монохроматического света контролируется в опорном канале фотоумножителем по свечению экрана, покрытого салицилатом натрия. Сигнал ФЭУ проходит усилитель постоянного тока, у которого последовательно с выходной нагрузкой включен транзистор T1 (см. рис. 1) электронной следящей системы.

Следящая электронная система работает в режиме, обеспечивающем протекание тока в обмотке реле РП-5 только при изменении входного сигнала $U_{\text {p }}$ транзистора $T 1$, уровень которого задается с помощью портенциометра $P 1$. 


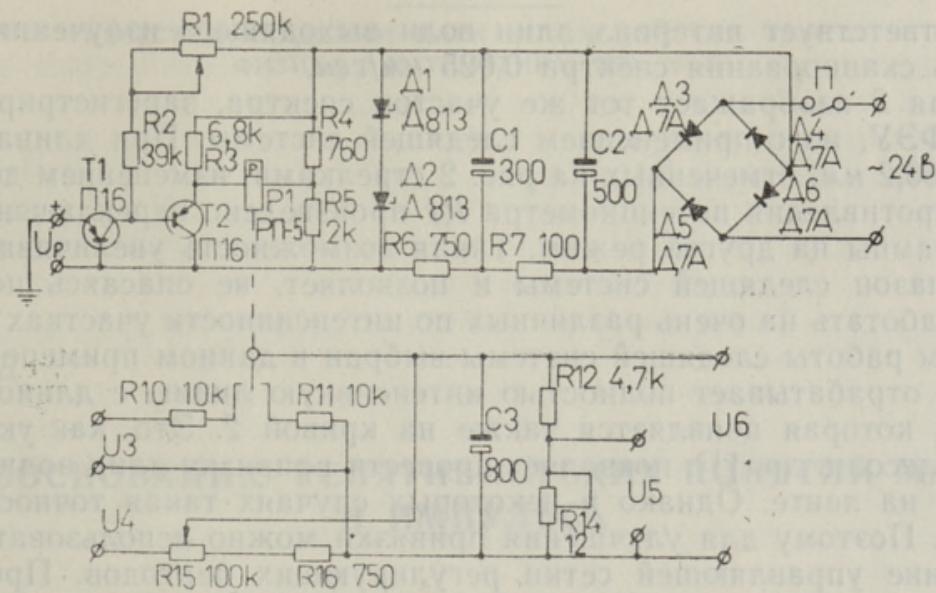

Рис. 1. Принципиальная схема элекпронной следящей системы.

Напряжение $U 6$, подаваемое на управляющие сетки регулирующих конечных пентодов источника питания водородной лампы, формируется на конденсаторе C3. Применяемый источник питания позволяет регулировать разрядный ток лампы в пределах от 10 до 600 ма (без высокочастотного поджига лампы).

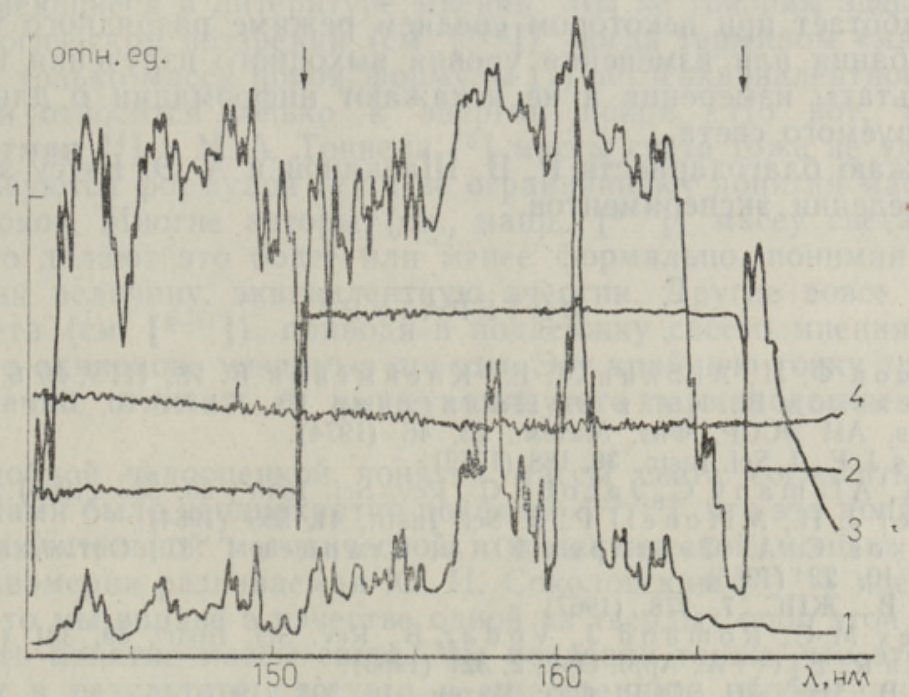

Рис. 2. Результаты испытания компенсационной системы регнстрапии.

Описываемая комбинированная система регистрации уже около семи лет успешно обслуживает двойной двухлучевой вакуумный монохроматор ДВМ-3 $\left[{ }^{10}\right]$. Результаты эксперимента приведены на рис. 2. Кривая 1 представляет собой часть спектра водородной лампы, зарегистрированную опорным ФЭУ при выключенной следящей системе и записанную на ленту электронного потенциометра. Ширина щелей по 0,09 мм, 
чему соответствует интервал длин волн выходящего излучения 0,3 нм. Скорость сканирования спектра 0,025 нм/сек.

Кривая 2 изображает тот же участок спектра, зарегистрированный

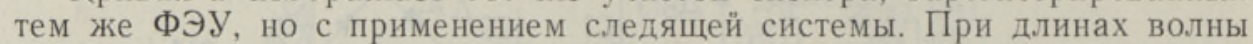
150,6 и 166,2 нм, отмеченных на рис. 2 стрелками, изменением действующего сопротивления потенциометра $R 1$ произведено переключение водородной лампы на другой режим. Такая возможность увеличивает рабочий диапазон следящей системы и позволяет, не опасаясь потухания лампы, работать на очень различных по интенсивности участках спектра.

Режим работы следящей системы выбран в данном примере так, что схема не отрабатывает полностью интенсивную линию с длиной волны 160,8 нм, которая появляется также на кривой 2. Это, как указывают Ф. И. Вилесов и др. [ $\left.{ }^{1}\right]$, позволяет провести привязку длин волн спектра к записи на ленте. Однако в некоторых случаях такая точность недостаточна. Поэтому для улучшения привязки можно использовать также напряжение управляющей сетки регулирующих пентодов. Пропоршиональное ему напряжение $U 5$ также записано на рис. 2 (кривая 3 ). Его сравнение с записью спектра 1 убеждает нас в возможности проведения идентификации длин волн по напряжению управляющей сетки лампы, регулирующей ток в цепи источника излучения.

Кривая 4 изображает отношение интенсивностей света измерительного и опорного каналов, записанное на ленту аналоговой делительной машины. Приемниками служили фотоумножители с экранами, покрытыми салицилатом натрия. Қак видно из рис. 2, почти двойное изменение выходного излучения практически не сказывается на ходе кривой 4 .

К достоинствам этой системы следует отнести то, что водородная лампа работает при некотором среднем режиме разрядного тока, причем колебания или изменения уровня выходного излучения не влияют на результаты измерения и не искажают информации о длине волны регистрируемого света.

Выражаю благодарность Р. В. Шацкиной и А. Э. Еэтсу за помощь при проведении экспериментов.

\section{Л Н T Е P A T Y P A}

1. Вилесов Ф. И., Акопян М. Е., Клейменов В. И., ПТЭ, № 6, 150 (1963).

2. Гребеньков В., Кыйв Э., Пыллуса а Ю., Тийт В., Шупенева Н., Изв. АН ЭССР, Физ. Матем., 23, 46 (1974).

3. J a m e s J. F., J. Sci. Instr., 36, 188 (1959).

4. Sys A., A l e m a n y C., J a cobs G., Rev. Sci. Instr., 36, 385 (1965).

5. C a rver J. H., Mitche 11 P., J. Sci. Instr., 41, 555 (1964).

6. Куликов С. А., Снигирев Ю. А., С тарцев Г. П., Опт.-механ. пром-сть, № 10,22 (1965).

7. Т и й т В., ЖПС, 7, 278 (1967).

8. Castex M.-C., Rom a nd J., Vod a r B., Rev. Sci. Instr., 39, 331 (1968).

9. O n a ka R., E j ir i A., Appl. Opt., 2, 321 (1963).

10. Ти йт В., Изв. АН ЭССР, Физ. Матем., 16, 393 (1967).

Ннститут физики

Академии наук Эстонской ССР
Поступила в редакцию 4/VI 1975 